\title{
Determining Supply Chain Safety Stock Level and Location
}

\author{
Bahareh Amirjabbari, Nadia Bhuiyan \\ Concordia University (Canada) \\ bahareh.amirjabbari@gmail.com,bbuiyan@alcor.concordia.ca
}

Received: September 2012

Accepted: December 2013

\section{Abstract:}

Purpose: The lean methodology and its principles have widely been applied in supply chain management in recent decades. Manufacturers are one of the most important contributors in a supply chain and inventory plays a paramount role for them to become lean. Therefore, there should be appropriate management of inventory and all of its drivers in accordance with a lean strategy. Safety stock is one of the main drivers of inventory; it protects against increasing the stretch in the breaking points of the supply chain, which in turn can result in possible reduction of inventory. In this paper an optimization model and a simulation model are developed and applied in a real case to optimize the safety stock level with the objective of logistics cost minimization.

Design/methodology/approach: In order to optimize the safety stock level while minimizing logistics costs, a nonlinear cost minimization safety stock model is developed in this paper and then it is applied in a real world manufacturing case company. A safety stock simulation model based on appropriate metrics in the case company's supply chain performance is also provided.

Findings: These models result in not only the optimum levels but also locations of safety stock within the supply chain.

Originality/value: In this research, two models of cost minimization and simulation have been developed and also applied in a real case company to result in not only optimized levels 
supply chain performance measurement metrics have been introduced in this paper and the simulation model is developed based on those.

Keywards safety stock, supply chain, lean, cost, optimization

\section{Introduction}

Applying the lean philosophy in a supply chain has received increasing attention from researchers in the last few decades. Contributors of a supply chain, no matter to which industry they belong, aim to follow the lean philosophy to make their business processes more and more efficient in order to survive on the market. Lean thinking is essentially about increasing efficiency, eliminating waste, and bringing new ideas by using empirical methods. Taylor (1999), Adamides, Karacapilidis, Pylarinou and Koumanakos (2008), Kainuma and Tawara (2006), Lamming (1996), Crino, McCarthy and Carier (2007), Wu and Wee (2009) did research on applying lean to the supply chain. There are also invaluable researches on the comparison of the lean paradigm with other methodologies in supply chain management such as Naylor, Naim and Berry (1999), Qi, Xuejun and Zhiyong (2007), and Mason-Jones, Nalor and Towill (2000).

Supply chain integration results in flow control which is essential in an operating system and such flow control is associated with inventory control (Slack, Chambers, Harland, Harrison \& Johnston, 1995; Gunasekaran, Patel \& Tirtiroglu, 2001; De Toni \& Tonchia, 2011). In addition, inventory is ones of the seven wastes introduced in lean philosophy that has to be tackled. Inventory plays a paramount role in manufacturers efforts to become lean. Therefore, one of the most important strategies to become lean for manufacturers is having efficient inventory within their chain. Chun Wu (2003), Cagliano, Caniato and Spina (2004), Wu (2009), McCullen and Towill (2001) studied on the application of lean in the manufacturing area.

Having an efficient level of inventory is a step towards increasing the inventory turnover in companies. According to the definition of turnover, decreasing the level of inventory helps to increase the turns. On the other hand, reducing inventory will lead to uncertainties and consequently stockouts (Natarjan \& Goyal, 1994). Therefore, safety stock is needed to protect against these kinds of uncertainties. Indeed, proper management of safety stock, as one of the most important drivers of inventory, has become critical objective towards leanness and having efficient inventory. Therefore, a manufacturing case company, who attempts to manage its inventory efficiently across the chain, has been selected in this paper and a safety stock optimization model has been proposed in order to optimize the levels and locations of safety stock within its chain. 
There are different objectives that an optimization safety stock can be built on such as minimization of cost, maximization of service level, and aggregate considerations (Silver, Pyke \& Peterson, 1998). Optimal determination approaches based on cost and service level objectives are more appropriate for practical applications (Inderfurth, 1991). Nowadays, firms are taking important steps towards an agreement on reducing total cost and inventories and increasing information sharing in order to improve the financial and operational performance of each channel of the supply chain (Maloni \& Benton, 1997). Logistics costs are more targeted in this regard as reducing costs of equipment, materials, and labor is difficult at best in today's competitive market (Long, Liu, Meng \& Chen, 2009). Therefore, minimization of logistics costs is also selected as the basis of the determination of optimum safety stock in this paper. Logistics costs are mainly related to procurement and supply, manufacturing process, and after sales service. Thus, holding and shortage costs are selected as representations of logistics costs in the optimization model.

Towards the goal of managing the supply chain properly, performance measurement and metrics play an important role in setting objectives, evaluating performance, and determining future actions (Gunasekaran, Patel \& McGaughey, 2004). Therefore, besides developing an optimization model, a safety stock simulation model is also provided in this paper to find the most appropriate levels and locations of safety stock for the case company under study by introducing its proper metrics for measuring supply chain performance.

A supply chain has different nodes such as different tiers of suppliers, producer, assembly, distributors, and end customer. Product availability is a critical measure for the performance of logistics and the supply chain (Coyle, Bardi \& Langley, 2009). One of the areas that has to be measured for the evaluation of suppliers in the context of the supply chain is the "flow" (Gunasekaran et al., 2004). Indeed, flow or in another word, product availability is a critical measure for the performance of logistics and the supply chain. There are different issues that cause disruptions and unavailability of products in the supply chain, as for example variability, whether in demand or lead time; quality issues; or internal and external issues such as low delivery performances, improper scheduling, inadequate product capacity, poor maintenance, among others. Therefore, safety stock is essential to compensate for the weakness of the supply chain for part availability and this factor has been considered in the selected safety stock optimization model of this study.

The challenge that we face in this paper is applying lean philosophy to the safety stock management within the supply chain for the purpose of reducing logistics costs. Therefore, for achieving the goal of having efficient safety stock across the supply chain and consequently reducing logistics costs, a safety stock cost minimization model and a simulation model are developed in this paper and then applied to a case company which is a manufacturer. 
In this paper, we apply a safety stock cost minimization model and also a simulation safety stock model in a case company which is a manufacturer. In the next section, we provide a review of the literature. In Section 3, we describe the case company. In Section 4, we introduce the optimization model, followed by the model formulation in Section 5. Results of the optimization model are then presented in the next section. In Section 7, the simulation model with performance measurement metrics are provided. We then provide a discussion of the results and their implications, and then conclude with some suggestions for avenues of future research.

\section{Literature Review}

There are many different methods and approaches in determining safety stock under different situations according to the literature. Aleotti Maia and Qassim (1998) proposed an optimization safety stock model with the objective of total inventory cost minimization. They also provided an analytical solution for finding the preferable case by comparing the inventory holding cost and opportunity cost. The conclusion was that holding inventory in the intermediate levels which only reduce the frequency of stockout is not economical.

A linear programming formulation with the control variables of safety stock was presented by Jung, Blau, Pekny, Reklaitis and Eversdyk (2008). This model aims to minimize the total supply chain's inventory and also meet the target of the service level. The interdependence between the service level at upstream and downstream stages of the supply chain, the nonlinear performance functions, and also the safety capacity constraint have been incorporated into this model. Linearization of the nonlinear functions has also been provided. Constant production capacity, zero lead time at the warehouse, and normally distributed demand are some of the assumptions applied in this model. In addition, raw material and transportation means have been assumed to be always available.

$\mathrm{Li}$ and $\mathrm{Li}$ (2009) presented a dynamic model of the safety stock in a Vendor Managed Inventory (VMI) system. Only the variability sourced by demand is considered in this model as the variability related to the suppliers disappear in the VMI system.

Zhao, Lai and Lee (2001) evaluated alternative methods in the determination of the safety stock level in multilevel MRP systems by using a simulation approach. In addition, the results of the evaluation of the relation between the safety stock multiplier and different system performance measures such as service level, schedule instability, and total cost in different methods has been provided.

Desmet, Aghezzaf and Vanmaele (2010) presented an approximation model for safety stock in a two-echelon distribution system which incorporates the variance of the central warehouse and the retailers in the replenishment lead time. In addition, the variance of the service time 
of the orders at the warehouse which has substantial effect on the system's lead time variance has been considered in this model.

Safety stock level and location determination in the supply chain with a stochastic environment is a challenging task; therefore, there are many different assumptions in the models and approaches provided in this area to make it simpler. For example, some of these approaches exclude the suppliers' variability, some of them have limitations in their applications, some of them put limitation on the demand distribution, among others. A general safety stock optimization model with the objective of logistics cost minimization by considering both internal and external variabilities is presented in this paper. This model is also considering the factor of part availability which is really critical in the chain.

Measurement of the supply chain performance is really critical for the success of any business as it deals with strategic, tactical, and operational planning and control. Supply chain performance determines the winner and measuring it facilitates the improvement of the overall chain's performance (Chen \& Paulraj, 2004). Based on the Deloitte report, although 91 percent of North American manufacturers recognized the supply chain management role as a critical one for the organizational success, only 2 percent of them are in the world class range for their supply chains (Thomas, 1999). Measuring the supply chain performance is challenging in essence of integrating quantitative and qualitative measurements and also making linkage between strategy and performance measurement (Shepherd \& Gunter, 2006).

Gunasekaran et al. (2004) developed a framework for supply chain performance measurement and metrics. They claimed the reason that many companies have not succeeded in maximizing their supply chain's potential is because of failing in developing the performance measures and metrics for enhancing the efficiency of their supply chain. They categorized the performance metrics into metrics for order planning, evaluation of supply link, metrics at production level, evaluation of delivery link, measuring customer service, and logistics cost.

Xia, Ma and Lim (2007) proposed an analytic hierarchy process (AHP) based methodology for supply chain performance measurement and highlighted some of the important metrics in this regard. They introduced four supply chain strategies that companies applied in case of competing in the market which are lean supply chain, agile supply chain, leagile supply chain, and adaptive supply chain. Then, they introduced the commonly used supply chain attributes that are reliability, responsiveness, flexibility, re-configurability, and cost. After that, they weighted these different attributes in each different supply chain strategies. They also used a fuzzy logic in case of measuring the qualitative measures and integrate them with the quantitative ones.

There are different metrics for measuring and assessing supply chain performance. Integrating them is a challenging task. In this study, the most appropriate metrics for this purpose have 
been introduced and a simulation safety stock model has been developed on their basis which supports the results of the optimization model.

\section{Case Study}

Nowadays, companies are becoming more and more interested in being lean to maintain competitiveness in the market. There are different areas within a company that could be improved towards making the company and its whole chain lean and leveraging from its benefits. One of the most important among these areas is the "inventory" of the company, which must be efficient according to lean principles. There are a number of different inventory drivers and safety stock is one of them. Indeed, the case company tries to manage the inventory across its supply chain efficiently, and towards this goal, efficient levels and locations of safety stock have become more and more highlighted as a prerequisite condition. Therefore, doing research on efficient management of safety stock, its model, and also applying it to the case company are the purposes of this paper. Cost minimization has been selected as the objective of the safety stock efficient model according to the desire of the case company's logistics management.

The company under study, which we will hereinafter refer to as $A B C$ for the purpose of confidentiality, is a manufacturer and leader in the aerospace industry. The company is characterized by high demand variability and long lead time, among others. $A B C$ is a multi-stage manufacturer. Tiers of suppliers, procurement, manufacturing, final assembly, and customers (internal and external) are different nodes of the $A B C^{\prime}$ s supply chain. The downstream nodes are the upstream nodes' customers, and the replenishment lead time of customer nodes is the order waiting time provided by their upstream nodes. In addition, ABC has a generally structured multi-stage system and there is no restriction with respect to the number of predecessors and successors of any node. Such multi-stage systems focus considerable attention on setting and positioning safety stock.

$A B C$ has two different manufacturing plants (MFs). The procurement department of the company is responsible for procuring the raw materials or semi- finished parts through suppliers to manufacturing plants or even supplying parts from one manufacturing plant to another (inter plants transfers). Indeed, the word "supplier" in the model could be the representative of the external supplier or internal manufacturing entity. It should be noted that procurement's location can be different from manufacturing ones. Finished parts from manufacturing entities have two internal customers that pull their outputs; they are Assembly (ASSY) and Aftermarket (AFM). These two latter entities are the last stages of the internal chain of the company just before the end customer. There are also some external supplied finished parts required for Assembly and Aftermarket that the procurement department is again in charge of supplying them. The Assembly entity has different finished product families 
with their own specifications. Therefore, if availability of parts (right parts at right time) can be assured for the internal customers, on-time delivery performance to the end customer will be assured as well. This availability should be guaranteed through safety stock, but the optimum safety stock level and location should also minimize logistics costs.

In order to apply the safety stock model to a real world case, preparing the most appropriate input data is critical to obtain the desired results. Data was collected through many different databases, company documentation and reports, company's SAP system, project meetings, and with the help of operational and strategic support personnel at $A B C$. Each set of information and data was collected from the appropriate logistics departmental personnel in the company. For example, logistics top managers provided the objective of the model and high-level process. The databases and metrics used will be discussed in more detail in the next sections.

This study provides considerable managerial experience, insights, and knowledge about how business firms deal with challenges in applying lean philosophy to safety stock management in supply chain towards minimizing logistics costs.

\section{Optimization Model Description}

The optimization model is presented through different possible value streams of each finished product family of the company and developed using lingo optimization software to result in the optimum level of safety stock with its optimum location in the stream. In order to limit the number of stages and for simplification, only the last two stages of those value streams that have more than two nodes before the internal customer stage are selected. Therefore, all the previous stages and their connections are being excluded and their performances are being captured only through the input of the latest second stage. The other reason for this limitation is the difficulty in defining the shortage costs in upstream stages of the chain due to lack of visibility and control. Furthermore, the objective of the model is cost minimization, and the upstream stages' contributions towards cost are significantly less than the downstream stages, thus this simplifying assumption should have a negligible effect on overall results. Although, there is a sample (Value Stream 4) presented in section 6 that goes beyond this limitation just to show the applicability of the model for the whole chain from end to end point.

Shortage cost, overage cost, and delivery performances are the inputs of the model. Different combinations of raw material (semi-finished part) and finished part are considered as indices in the model based on the selected value streams. 


\section{Optimization Model Formulation}

For all value streams, the notations of the model are as follows:

a. Sets and Indices

$i \quad$ Raw material/ semi-finished part

$p \quad$ Finished part

$u \quad$ Customer (ASSY, AFM)

b. Variables

$K_{i} \quad$ Delivery performance of procurement to manufacturing

$K_{p} \quad$ Delivery performance of manufacturing or procurement to customers

c. Parameters

$P_{i} \quad$ Supplier delivery performance to procurement

(If supplier is a manufacturing plant, $\mathrm{P}_{\mathrm{i}}$ would be manufacturing performance for semifinished part)

$P_{p} \quad$ Manufacturing performance for finished part

(Ratio between on time manufactured and planned manufacture of finished part)

- It should be noted that index of " $p$ " is used for only those finished parts that are manufactured in $A B C$. Indeed, for those finished parts that are supplied through suppliers, index of " $\mathrm{i}$ " is used.

$C_{S} \quad$ Cost of shortage

$C_{O} \quad$ Cost of overage

$x_{i} \quad$ Raw material/semi-finished part safety stock

$x_{p} \quad$ Finished part safety stock

$q_{i} \quad$ Raw material/semi-finished part quantity ordered

$q_{p} \quad$ Finished part quantity ordered

$q^{*} \quad$ On-time delivered quantity of raw material/ semi-finished part or finished part

Figures 1 to 3 present variables and parameters in possible value streams for procuring a part to the customer in the case company. 


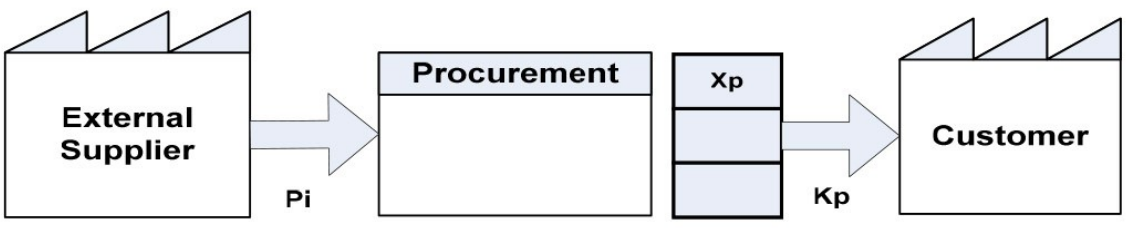

Figure 1. Variables and parameters in value stream

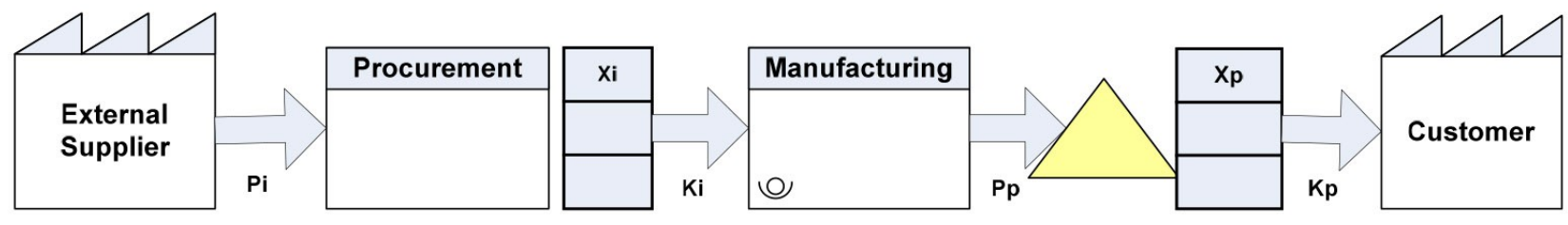

Figure 2. Variables and parameters in value stream

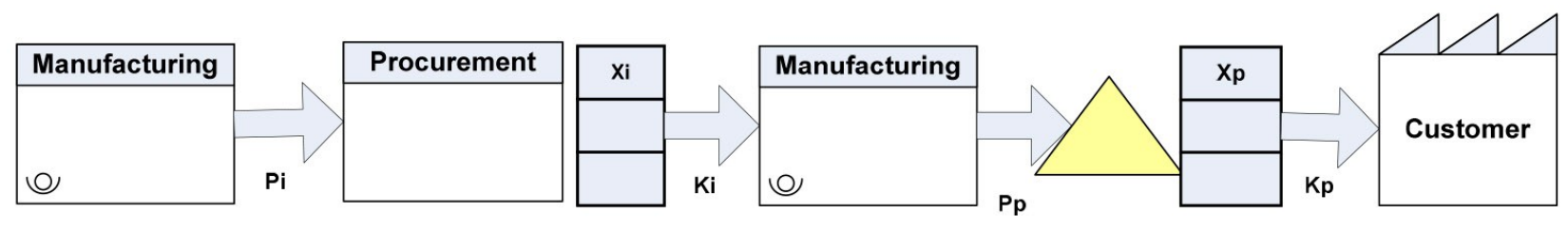

Figure 3. Variables and parameters in value stream

$\mathrm{Ki}$ is the summation of the availability percentage of raw material/semi-finished part for manufacturing through procurement based on the absolute suppliers' performances $(\mathrm{Pi})$ and the availability percentage of procurement's safety stock for that part (xi/qi). Indeed, procurement can deliver whatever quantities they received on time through suppliers plus their safety stock to the manufacturing. $\mathrm{Kp}$ is the summation of the availability percentage of the finished part which is dependent on the manufacturing performance ( $P p)$ and also their previous stages' performances (Ki) and the availability percentage of manufacturing's safety stock for that part (xp/qp). Likewise, manufacturing can deliver whatever quantities of finished parts they can produce on time which is also dependent on the deliveries of their previous stages in the chain plus their own safety stock quantities to their customers (ASSY and AFM).

The related formulas of $\mathrm{Ki}$ and $\mathrm{Kp}$ are as (1) and (2):

$$
\begin{gathered}
K_{i}=P_{i}+x_{i} / q_{i} \\
K_{p}=P_{p} \times K_{i}+x_{p} / q_{p}
\end{gathered}
$$

In the cases that the finished part is directly procured through the external supplier for the customers, Kp formula will be equal to (1). 
$\mathrm{Pi}$ and $\mathrm{Pp}$ are calculated as average numbers based on historical data from the last year. $\mathrm{A}$ report called the First Filled Rate (FFR) is used for calculation of these parameters. This report is used to present the availability of the right part at the time that is required. The FFR result takes into account the total on hand stock in its calculation which does include safety stock as well. It should be noted that $\mathrm{Pi}$ and $\mathrm{Pp}$ should be the absolute delivery performance of supplier and manufacturing without the contribution of the safety stock that may be used during last year. Therefore, the safety stock has been excluded from the FFR report for this purpose. In addition, when there are two stages in the selected value stream, the FFR report also includes the contribution of the last second stage's performance in its results for calculating the last stage's performance which is manufacturing. Therefore, this must also be excluded. Hence, to calculate the required absolute value of Pp from FFR, three other parameters should be defined. First one is $K^{\prime} p$ which is the exact number extracted through FFR, the other one is $P^{\prime} p$ which is the FFR's result excluding safety stock contribution. And the third one is $K^{\prime} i$ which is the historical previous stage's delivery performance; by dividing P'p by this parameter the absolute manufacturing performance is measured $\left(P p=P^{\prime} p / K^{\prime} i\right)$. Table 1 is a snapshot of a sample FFR and presents the formulas used to eliminate the safety stock from its calculation. As shown through the table, in the 12 th week of 2010 , the FFR report gives $100 \%\left(K^{\prime} p=100 \%\right.$ ) as the delivery performance of manufacturing to its customer because it takes into account the 300 pieces of safety stock for meeting the past and current requirements; however, safety stock must be excluded through this calculation and P'p becomes $18 \%$. The next step for calculating the absolute manufacturing performance would be the elimination of the effect of the previous stage's performance $\left(\mathrm{K}^{\prime} \mathrm{i}\right)$.

\begin{tabular}{|c|c|c|c|c|c|c|c|c|c|c|}
\hline $\begin{array}{c}\text { Part } \\
\text { Cod } \\
e\end{array}$ & Entity & $\begin{array}{l}\text { Calendar } \\
\text { Week }\end{array}$ & Stock & $\begin{array}{c}\text { Required } \\
\text { Past }\end{array}$ & $\begin{array}{l}\text { Required } \\
\text { Current }\end{array}$ & $\begin{array}{l}\% \text { Met } \\
\text { Global } \\
\text { (K'p) }\end{array}$ & $\begin{array}{c}\text { Theoretical } \\
\text { Safety } \\
\text { Stock }\end{array}$ & $\begin{array}{c}\text { Safety } \\
\text { Stock } \\
\text { On- } \\
\text { Hand }\end{array}$ & $\mathbf{q}^{*}$ & $P^{\prime} \mathbf{p}$ \\
\hline AF 1 & MF & 11.2010 & 2100 & 500 & 500 & 100 & 0 & 0 & 500 & $100 \%$ \\
\hline AF 1 & MF & 12.2010 & 1100 & 700 & 560 & 100 & 300 & 300 & 100 & $17.85 \%$ \\
\hline
\end{tabular}

Table 1. First fill rate report sample

The inventory strategy of $A B C$ for the parts with high cost and low volume is MRP system. Based on this, a safety stock strategy is really required for this latter category of parts. For calculating $\mathrm{q}_{i}$ and $\mathrm{q}_{\mathrm{p}}$, we need to understand the risk period. Risk period consists of a review period and replenishment lead time (Tempelmeier, 2006). The review period is the basis on which the company updates its data. Of course the review period has an effect on the duration that the company should wait to receive its order through the supplier to be replenished. In the case company of this paper the data are updated daily; therefore, there is no need for defining the review period for that. Consequently for parts managed by the 
MRP system, quantities within the replenishment lead time have found as the most appropriate definition for $q_{i}$ and $q_{p}$ to result in the proper level of safety stock for the company through the model. In essence, if changes happen in demand within this period (replenishment lead time), we cannot count on the suppliers' support $100 \%$ of the time. Safety stock is required for coverage of this variability. The first step for their calculation would be identifying the planned order quantity of each specific part (raw/semi or finished part) per week according to its planning parameters. And these planning parameters are related to ordering policies of each part. The second step would be the calculation of the average weekly forecast demand of that specific part for the next year. After that, the division of the planned order quantity and average weekly demand would result in the replenishment lead time in weeks. When changes happen in the supply chain such as changes in the demand or capacity ration, entrance of new competitors, introduction of a new product, or retirement of a matured one, the safety stock required for the supply chain must be re-evaluated (Jung et al., 2008). ABC has decided to run the model and update it every quarter, therefore, the weekly demand of the next quarter would be merged based on the calculated replenishment lead time. And finally, the maximum quantity of this combination will be selected as $\mathrm{q}_{\mathrm{i}} / \mathrm{q}_{\mathrm{p}}$ in order to allow the safety stock strategy to support the worst case.

One of the advantages of this method of calculating $q_{i}$ and $q_{p}$ is making the market variability involved by taking into account the forecast demand.

Shortage costs (costs of safety stock violation) have different definitions for raw materials (semi-finished parts) and finished parts as they are located in different stages within the chain and their shortages have different effects on the system. The shortage cost of the raw material (semi-finished part) is the summation of the expediting cost on the supplier, expediting cost on transportation, and overtime of the manufacturing section. On the other hand, shortage of the finished part which is required by Assembly, causes disruptions and stock not pulled for all the other parts related to that finished part and also its finished product in different locations of the supply chain. In addition, shortage of the finished part causes the finished assembled product to be held up unreleased. Therefore, the shortage cost is defined as follows:

$\mathrm{C}_{\mathrm{sp}}=$ (Standard cost of the finished assembled product $*$ average days of holding finished assembled product due to the shortage of the specific finished part during last year *0.1)/365

Coefficient of $10 \%$ in the above formula is the annual interest rate that company could receive by putting this amount of money in the bank, although the company has this as inventory buckets instead of cash right now.

The cost of shortage of the finished part required by Aftermarket is defined as the profit that the company will lose by not having the part ready to deliver on time to the customer, which is 
the direct cost. Besides that, there are many intangible effects of this shortage that are called indirect costs and are difficult to gauge accurately (Graves \& Rinnooy Kan, 1993). One of them is loss of customers' goodwill that may turn them to other competitors in the future.

The cost of overage is defined as the interest that the company is losing by holding inventory instead of having it in cash. Hence, it is the multiplication of standard cost of the part and the annual interest rate $(10 \%)$.

As can be seen through the formulas and definitions, a period of one year has been selected for historical data collection. As the factors (such as shortage cost and delivery performances) that are gathered within this time frame are critical to make an appropriate decision about the level and location of safety stock, one year has been selected in order to have a sufficient window view.

Some samples of value streams associated with their models' formulas are presented below.

Value stream 1 shown in Figure 4 consists of one raw material/semi-finished part used to make one finished part which has two customers, ASSY and AFM. The corresponding objective function and constraints are presented by (3).

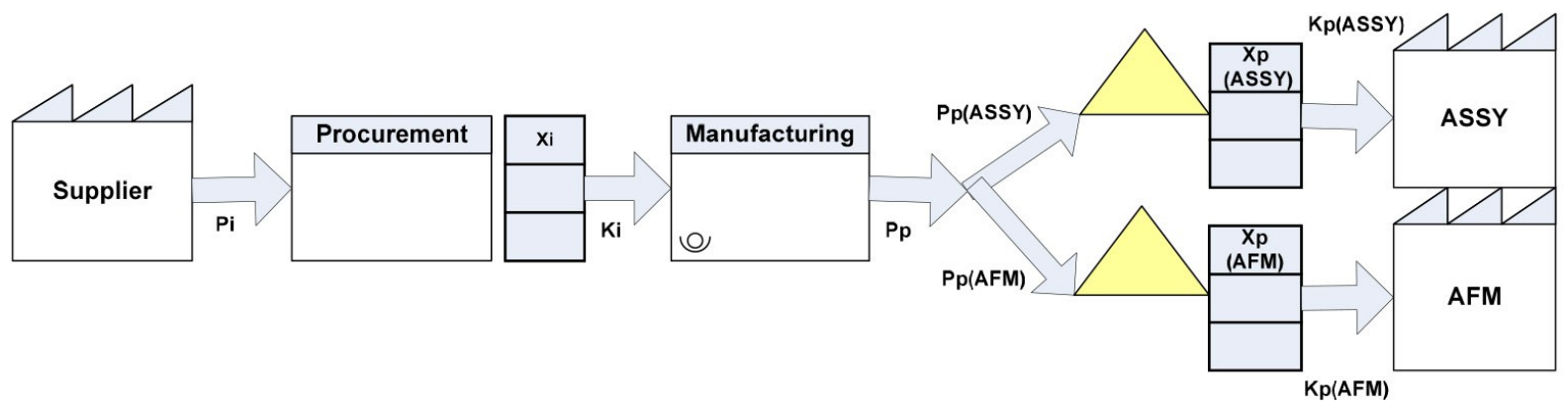

Figure 4. Value stream 1

$$
\begin{aligned}
& \operatorname{Min} C=C_{s i} q_{s i}\left(1-p_{i}\right)+C_{o i} q_{i}\left(K_{i}-P_{i}\right)+\sum_{u=1}^{2} C_{s p u} q_{p u}\left(1-K_{p u}\right)+\sum_{u=1}^{2} C_{o p u} q_{p u}\left(K_{p u}-\left(P_{p u} \times K_{i}\right)\right) \\
& +\sum_{u=1}^{2} C_{o p u} q_{p u}\left(K_{p u}-\left(P_{p u} \times K_{i}\right)\right)
\end{aligned}
$$

SubjectTo:

$$
\begin{array}{ll}
K_{i} \leq 1 & \\
K_{i} \geq P_{i} & \\
K_{p u} \leq 1, & u=1,2 \\
K_{p u} \geq P_{p u} \times K_{i} & u=1,2
\end{array}
$$

The objective function is minimization of the total logistics cost. The first part of the equation is shortage cost of raw material. $C_{s i}$ is the unit shortage cost of raw material, $q_{i}$ is the quantity 
ordered for the raw material, and $\left(1-\mathrm{P}_{\mathrm{i}}\right)$ is the shortage possibility. The second part of equation is holding cost of raw material. $\mathrm{C}_{0}$ is the unit overage cost of raw material, $\mathrm{q}_{\mathrm{i}}$ is the quantity ordered, and $\left(\mathrm{k}_{\mathrm{i}}-\mathrm{p}_{\mathrm{i}}\right)$ is the overage possibility. Likewise, the other two parts of the function are related to the shortage cost and holding cost of the finished part for two customers.

The constraints of the model are about the boundaries for the delivery performances. The upper bounds for both $K_{i}$ and $K_{p}$ are $100 \%$. The lower bound for $K_{i}$ is equal to the supplier delivery performance $\left(P_{i}\right)$. Indeed, the lowest delivery performance of the raw material from the procurement to the manufacturing is the availability of that part through the supplier without safety stock. The lower bound for $K_{p}$ is the multiplication of the previous stages' performances which are $\mathrm{P}_{\mathrm{p}}$ and $\mathrm{K}_{\mathrm{i}}$.

If for this case, there were two different kinds of finished parts but again in demand with both customers, then there should be a summation on both indices of finished part ( $p$ ) and customer (u) in the objective function.

In value stream 2 which is shown in Figure 5, two raw materials/semi-finished parts are used to make one finished part which has two customers, ASSY and AFM. The corresponding model is also presented by (4).

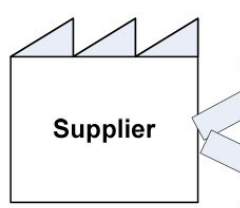

Pi2

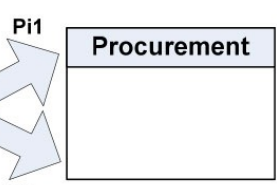

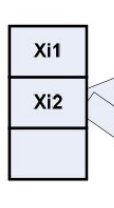

Ki2

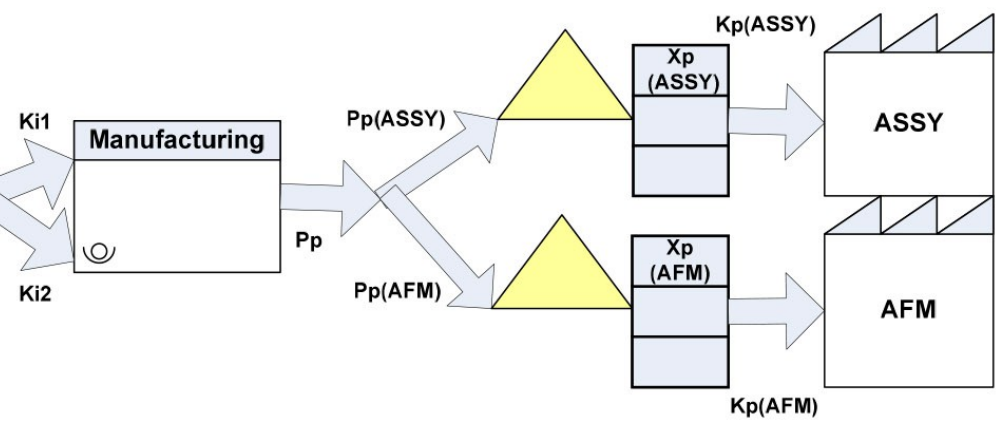

Figure 5. Value stream 2

$$
\begin{aligned}
& \operatorname{Min} C=\sum_{i=1}^{2} C_{s i} q_{i}\left(1-P_{i}\right)+\sum_{i=1}^{2} C_{o i} q_{i}\left(K_{i}-P_{i}\right) \\
& +\sum_{u=1}^{2} C_{s p u} q_{p u}\left(1-K_{p u}\right) \\
& +\sum_{u=1}^{2} C_{o p u} q_{p u}\left(K_{p u}-\left(P_{p u} \prod_{i=1}^{2} K_{i}\right)\right)
\end{aligned}
$$




\section{SubjectTo:}

$$
\begin{array}{ll}
K_{i} \leq 1, & i=1,2 \\
K_{i} \geq P_{i}, & i=1,2 \\
K_{p u} \leq 1, & u=1,2 \\
K_{p u} \geq P_{p u} \prod_{i=1}^{2} K_{i}, & u=1,2
\end{array}
$$

As before, if there were two different finished parts for the same situation, the model would be changed.

As can be seen through the constraints of the model, the company's objective is to have $100 \%$ delivery performances. Therefore, the upper boundaries of both stages are assigned to $100 \%$ in order to not to allow the model to impose a shortage to the system. Of course, these upper bounds could be less than 1 based on the service level goals in different cases.

By this definition of the model, costs factors would be the indicators for the location of the safety stock and its level would be identified based on the boundaries of the delivery performances. Figures 6 and 7 are two sample feasible regions of the linear model to illustrate the varying of the safety stock location based on the optimal point. In addition, Table 2 presents the comparison between the costs in each case and also the recommended location of the model for the safety stock. The assumptions applied in the model in these cases are linearity, having only one customer for finished part, and equality of $q_{i}$ and $q_{p}$. The optimization model will be linear if there is only one raw material/semi-finished part and optimum point with minimum cost will happen only in one of the four boundaries; therefore, the linearity assumption is used in this section. In addition, it would be easier to depict the feasible regions by the assumption of having only one customer. The coefficients of the variables in the optimization model are costs and order quantities; so, the equality assumption of the order quantities is used for eliminating their contributions in the comparisons and highlighting the role of costs in determining the optimal location of safety stock. 


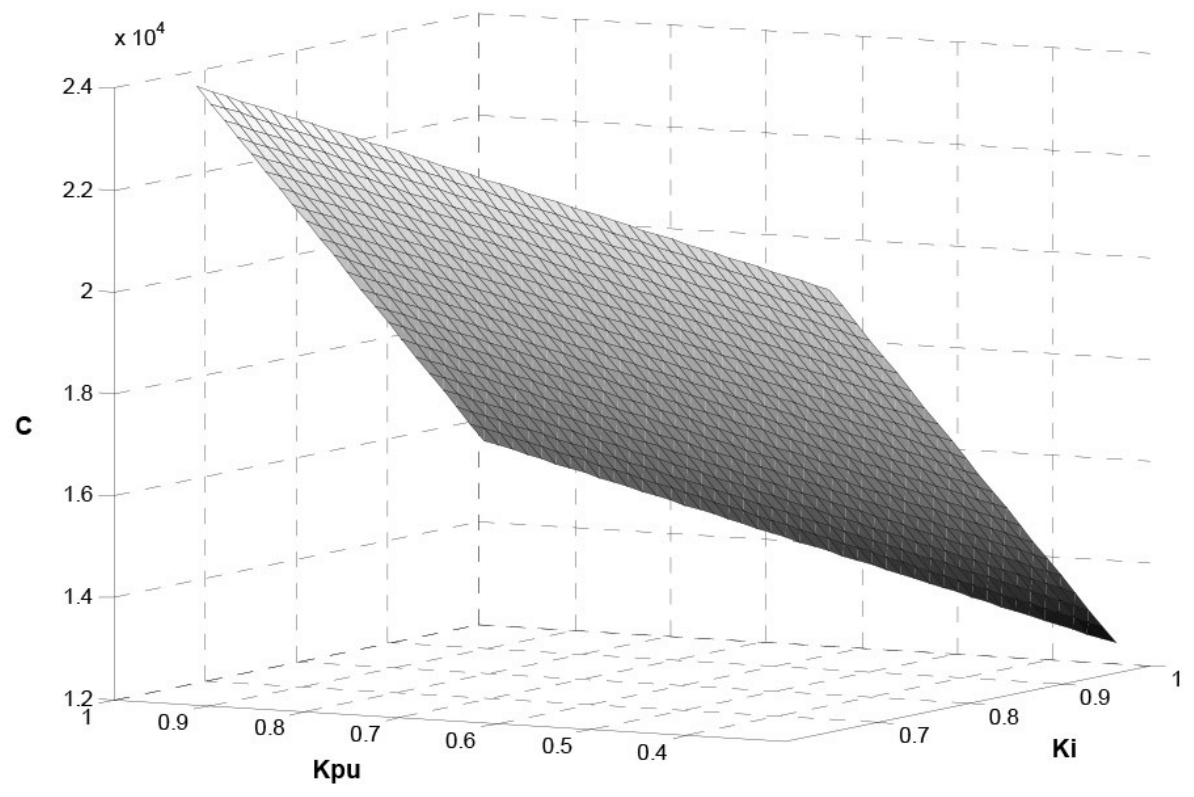

Figure 6. Location of safety stock-Case 1

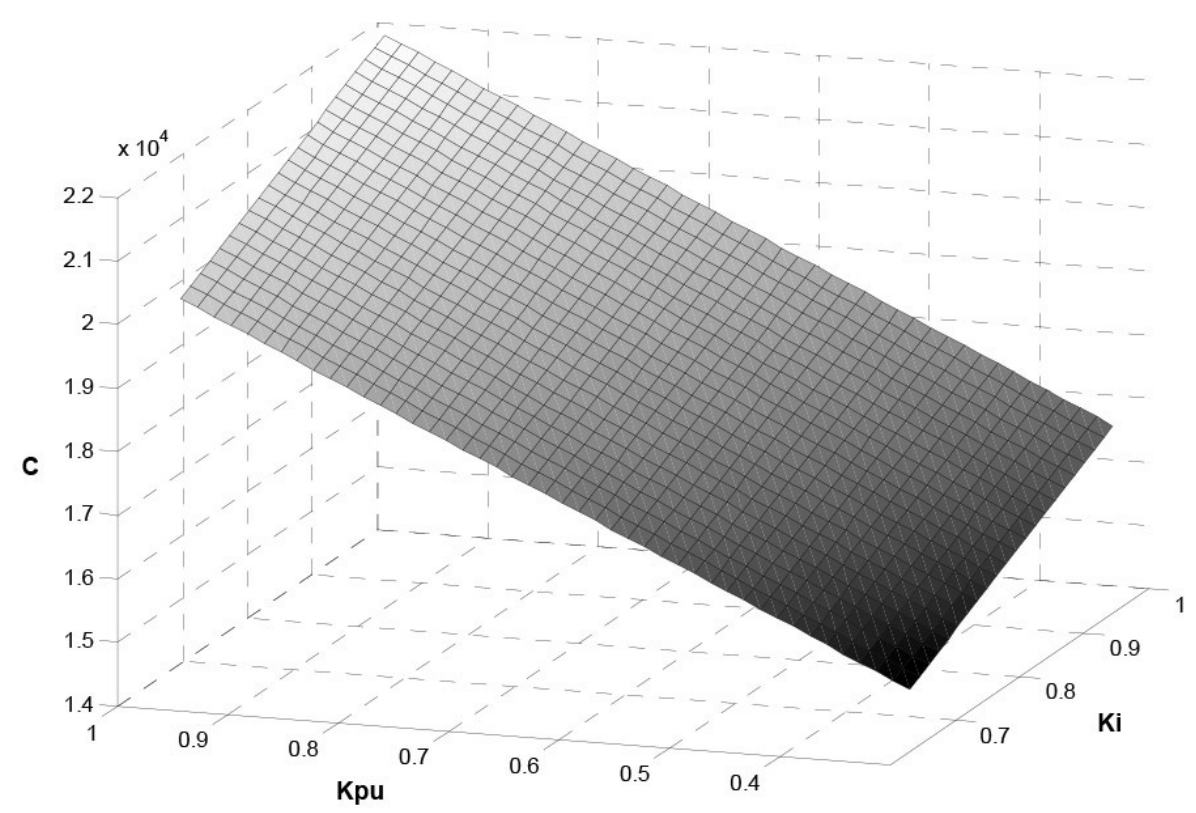

Figure 7. Location of safety stock-Case 2

\begin{tabular}{|c|c|c|c|}
\hline Case & Costs Comparison & Safety Stock for Raw Material & Safety Stock for Finished Part \\
\hline 1 & Cop $>$ Csp $>$ Csi $>$ Cos & Yes & No \\
\hline 2 & Cop $>$ Csp $>C s i>C o s$ & No & No \\
\hline
\end{tabular}

Table 2. Cost comparison and safety stock locations 
In order to make the results of the model more effective for the company, one of the most problematic finished product families of the Assembly was selected, and value streams of its finished parts that are going to be assembled were reviewed with the model. As each of the selected final product families could have 100 different value streams in the case company, it was decided to apply the optimization model only to those value streams that end with finished parts that were consistently in shortage report during last year in order to limit samples. Value streams of these pacer parts vary. Some of them could have only the supplier stage before the assembly and some others could be very long. As discussed before, these long value streams were limited by taking into account only parts of level 1 and 2 of its finished product's bill of materials (BOM).

\section{Optimization Model Computational Results}

Results of the model applied to some value stream samples of one finished product family in the company are presented in Table 3. This table includes input factors to the model such as delivery performances $\left(P_{i}, P_{p}\right)$, parts quantities $\left(q_{i}, q_{p}\right)$, costs $\left(C_{s}, C_{0}\right)$ along with parameters required to calculate them $\left(\mathrm{K}^{\prime}{ }_{i}, \mathrm{P}_{\mathrm{p}}^{\prime}, \mathrm{K}_{\mathrm{p}}^{\prime}\right.$, standard cost) for each value stream. This table also presents the old and new safety stock levels and total costs (for those cases that all required data were available) to compare previous situation with new one. All historical data presented in this table, as mentioned before in section 5, are based on last year records. Lingo 11.0 was used to solve the non-linear optimization model. It should be mentioned that due to confidentiality, masked data are used in this paper.

\begin{tabular}{|c|c|c|c|c|c|c|c|c|c|c|c|c|c|c|c|c|c|c|}
\hline $\begin{array}{l}\text { Value } \\
\text { Stream }\end{array}$ & $\begin{array}{l}\text { Part } \\
\text { Code }\end{array}$ & Entity & $\mathbf{K}^{\prime} \mathbf{i}$ & $\mathbf{P i}$ & qi & $\mathbf{P}^{\prime} \mathbf{p}$ & $\mathbf{P p}$ & $q p$ & $\mathbf{K}^{\prime} \mathbf{p}$ & $\begin{array}{l}\text { Stnd } \\
\text { Cost }\end{array}$ & Cs & Co & Old xi & $\begin{array}{c}\text { New } \\
\text { xi }\end{array}$ & $\begin{array}{c}\text { Old } \\
\text { xp }\end{array}$ & $\begin{array}{c}\text { New } \\
\text { xp }\end{array}$ & $\begin{array}{c}\text { Total } \\
\text { Old } \\
\text { Cost }\end{array}$ & $\begin{array}{l}\text { Total } \\
\text { New } \\
\text { Cost }\end{array}$ \\
\hline VS1 & G & MF & 0.30 & 0.30 & 12 & & & & & $\$ 3,000$ & $\$ 45$ & $\$ 300$ & 0 & 0 & & & \multirow{3}{*}{$\$ 150,378$} & \multirow{3}{*}{$\$ 6,378$} \\
\hline VS1 & AG & ASSY & & & & 0 & 0 & 10 & 0 & $\$ 6,000$ & $\$ 15,000$ & $\$ 600$ & & & 0 & 10 & & \\
\hline vS1 & AG & AFM & & & & 0 & 0 & 0 & 0 & $\$ 6,000$ & $\$ 24,000$ & $\$ 600$ & & & 0 & 0 & & \\
\hline vS2 & $\mathrm{H}$ & MF & 0.15 & 0.15 & 10 & & & & & $\$ 4,000$ & $\$ 80$ & $\$ 400$ & 0 & 9 & & & & \multirow{3}{*}{$\$ 3,400$} \\
\hline vS2 & $\mathrm{AH}$ & ASSY & & & & 0.25 & 1 & 6 & & $\$ 10,000$ & $\$ 800$ & $\$ 1,000$ & & & 1 & 0 & & \\
\hline VS2 & $\mathrm{AH}$ & AFM & & & & 0.38 & 1 & 5 & & $\$ 10,000$ & $\$ 40,000$ & $\$ 1,000$ & & & 1 & 0 & & \\
\hline vS3 & I & MF & 0.18 & 0.18 & 8 & & & & & $\$ 3,500$ & $\$ 36$ & $\$ 350$ & 0 & 7 & & & & \multirow{2}{*}{$\$ 13,246$} \\
\hline vS3 & AI & ASSY & & & & 0.05 & 0.27 & 6 & & $\$ 25,000$ & $\$ 8,000$ & $\$ 2,500$ & & & 1 & 5 & & \\
\hline VS4 & $\mathrm{T}$ & $\mathrm{MF}$ & 0.70 & 0.59 & 25 & & & & & $\$ 2,000$ & $\$ 15$ & $\$ 200$ & 6 & 10 & & & \multirow{5}{*}{$\$ 1,249$} & \multirow{5}{*}{$\$ 468.96$} \\
\hline VS4 & L & MF & & & & 0.30 & 0.43 & 12 & 0.50 & $\$ 300$ & $\$ 25$ & $\$ 30$ & & & $4 \& 3$ & 7 & & \\
\hline VS4 & $\mathrm{N}$ & MF & 0.70 & 0.53 & 12 & & & & & $\$ 90$ & $\$ 2$ & $\$ 9$ & $14 \& 0 \& 5$ & 6 & & & & \\
\hline VS4 & $\mathrm{s}$ & $\mathrm{MF}$ & 0.95 & 0.95 & 10 & & & & & $\$ 160$ & $\$ 8$ & $\$ 16$ & 0 & 1 & & & & \\
\hline VS4 & ALNS & ASSY & & & & 0.59 & 1 & 5 & 0.85 & $\$ 3,500$ & $\$ 500$ & $\$ 350$ & & & $6 \& 3$ & 0 & & \\
\hline
\end{tabular}

Table 3. Computational results 
Value stream 4 of Table 3 shows one of the class A finished parts (ALNS) required for Assembly for the selected product family. This finished part has three semi-finished parts (level 2 in finished product's BOM which are $L, N$, and $S$ in Table 3). " $L$ " is an in-house part and is manufactured in $A B C$. Furthermore, the manufacturing plant requires raw material ( $T$ ) to produce this part which is procured through the supplier. Part $T$ is in level 3 in the BOM. Therefore, this sample goes far beyond the limitation of levels 1 and 2, and shows that the model is applicable for all stages of the value streams as long as the input data of the model are provided.

Manufacturing, receives the two other semi-finished parts ( $\mathrm{N}$ and $\mathrm{S}$ ) required for producing the finished part directly through suppliers. Figures 8 and 9 present the respective value stream and BOM.

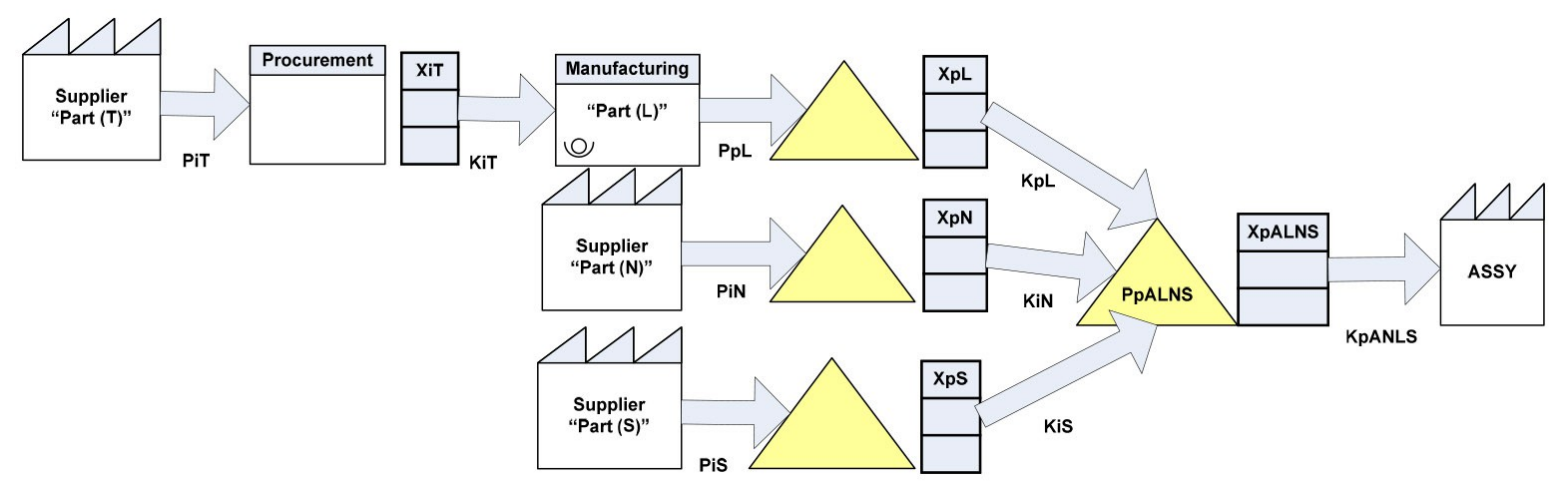

Figure 8. Value stream

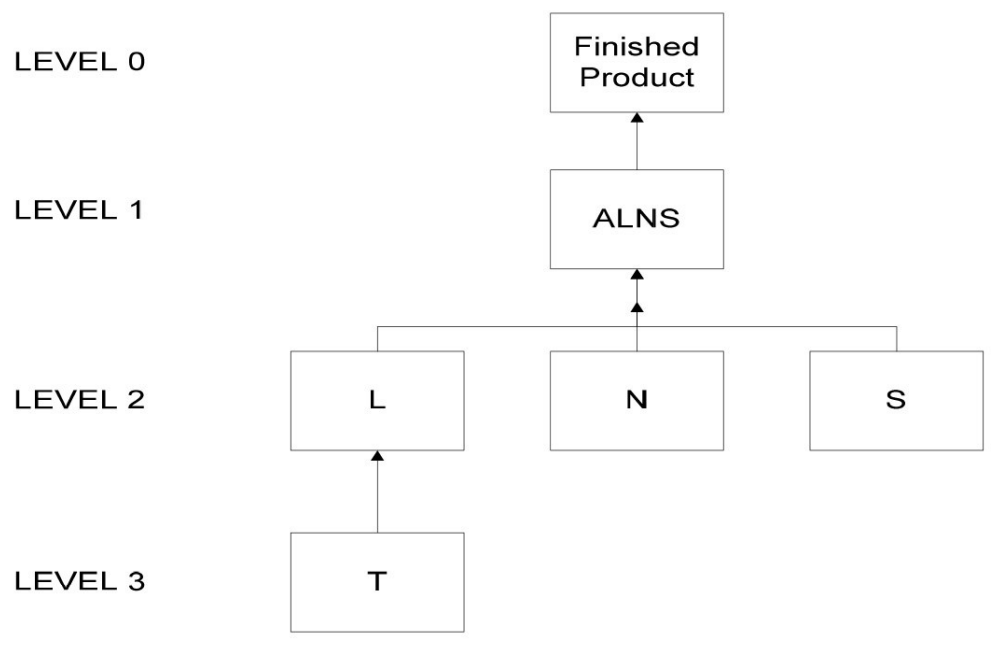

Figure 9. BOM

This last value stream (value stream 4), can be a representative case to illustrate the error and especially in this case, the overestimating of safety stock result in the analysis of parts in isolation and not within the chain. If, ALNS was being considered separately and apart of its chain, system may allocate some level of safety stock for that due to the $\mathrm{K}^{\prime}{ }_{\mathrm{p}}$ which is $85 \%$. But, 
when this part is analyzed within its chain, it is understood that the reason for no availability of the finished part is not due to the last stage performance but it is due to the low delivery performances of the semi-finished parts. Therefore, keeping safety stock in the last stage only increases the holding cost of the system.

An analysis of the results shows that the weakness of the supply chain must be compensated with safety stock, while it is optimized to meet the desired objective of the business. It has been shown in this paper that in optimizing the safety stock based on a cost minimization objective, not only its level but also its location in the supply chain is important. In fact, by keeping safety stock in upstream stages, there will be savings in holding costs. On the other hand, by keeping safety stock in downstream stages, there will be savings in lead time. Therefore, these two options must be traded off towards optimizing safety stock location for minimizing the total logistics costs. Through this procedure, any business can improve its profitability and also become a superior competitor with its chain.

\section{Simulation Model}

Besides developing an optimization model, a simulation model is also provided by introducing and assessing the relevant metrics of the case company's supply chain for finding the most appropriate level and also location of safety stock with the objective of total logistics cost minimization. This safety stock simulation model sustains the results of the optimization model. The simulation safety stock model consists of some matrices that allow us to assess the performance of any stages of the supply chain in a matter of safety stock level and location. It should be noted that all data that are presented in the tables of this section are the masked data due to confidentiality.

As a first step, metrics used at the company for measuring the performances of its supply chain were collected to help build the simulation model. The first one is called On-Time Delivery (OTD) which shows the delivery performance of the supplier (internal or external) to its customer(s) (internal or external). However, this metric is not the best one for three main reasons. The first reason is that OTD is not capturing the expeditions of purchase orders. The second reason is that the OTD does not consider quality problems. The last reason is related to the incorporation of safety stock in OTD's calculation for delivery performances that does not result in the pure delivery performances.

Therefore, another metric called First Fill Rate (FFR) which has been already defined in the optimization safety stock model will be used in our simulation model. It should be noted that OTD and FFR are calculated based on the last six months' records. FFR would be the average of this record, but OTD is calculated as the "weighted average" as it is being reported with the percentage aligned with deliveries. 
The third metric is the length of Lateness which represents how many days a specific part is delivered late to its customer within the supply chain. Length of Lateness is equal to Posting Date minus Statistical Date.

The fourth metric is the Safety Stock Coverage (in weeks) which is calculated by dividing each part's safety stock's quantity into its weekly requirements (demand).

And finally the last metric is the information extracted from the quality report which reports the parts that have quality issues and creating the bucket called quality lot. This report includes quality issue creation date, quality issue completion date, and quantity of parts with quality issues.

In order to develop the desired simulation safety stock model, safety stock's distribution within the supply chain has to be found to determine if it is located properly with the support of the defined metrics. Hence, as a first step, a matrix has been developed as shown in Table 4. This table includes different finished products of the company in the row and the contributors of the supply chain in the column and the value of the safety stock related to each combination of the product and supply chain contributor. More specifically for the case under study, the pivot table would be as of Table 5 .

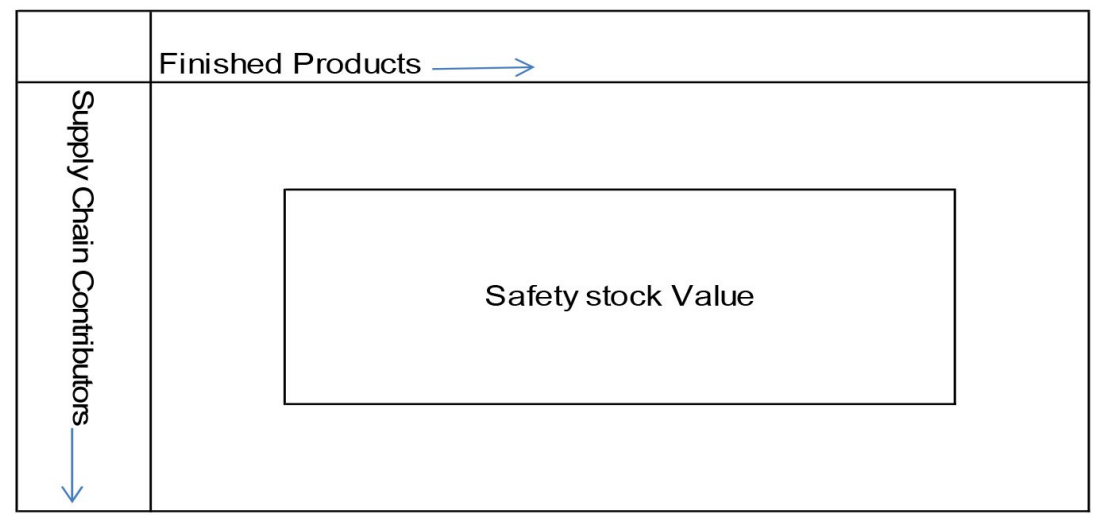

Table 4. Safety stock distribution pivot table template

\begin{tabular}{|l|r|r|r|r|r|}
\hline \multicolumn{7}{|c|}{ Sum of SS Value Split } \\
\hline Supply Chain Contributors & \multicolumn{1}{c|}{ AB } & \multicolumn{1}{c|}{ AE } & \multicolumn{1}{c|}{ AF } & \multicolumn{1}{c|}{ ACD } & \multicolumn{1}{c|}{ AG } \\
\hline Procurement & $\$ 107,170$ & $\$ 105,870$ & $\$ 726,680$ & $\$ 290,340$ & $\$ 125,780$ \\
\hline Manufacturing & $\$ 566,120$ & $\$ 348,420$ & $\$ 235,596$ & $\$ 65,072$ & $\$ 91,400$ \\
\hline Assembly & $\$ 42,170$ & $\$ 9,194$ & $\$ 7,800$ & $\$ 17,500$ & $\$ 14,012$ \\
\hline Grand Total & $\$ 715,460$ & $\$ 463,484$ & $\$ 970,076$ & $\$ 372,912$ & $\$ 213,192$ \\
\hline Sales Volume $(\$ M)$ & $\$ 25$ & $\$ 40$ & $\$ 105$ & $\$ 27$ & $\$ 26$ \\
\hline
\end{tabular}

Table 5. Case company's safety stock distribution pivot table 
And then the total value of safety stock of each finished product will be compared with its total value of sales in the past (for example last year) and this comparison will give us an idea of whether the current value of safety stock for each finished product is aligned with its sales value or not. It may be even determined that the same value of safety stock is keeping for two different finished products while the sales value of one was even twice of the other one. For example, although the volume of finished product $A B$ is really lower than the volume of $A F$, still the value of its safety stock $(\$ 715,460)$ is somehow equal to the safety stock value of AF $(\$ 970,076)$. On the other hand, it is shown that manufacturing makes the biggest portion of AB's safety stock value $(\$ 566,120)$. Therefore, this pivot table (Table 5 ) will give us a direction for more investigation.

The next matrix that is required to help find the most appropriate location of safety stock would be a table with the combination of OTD and Length of Lateness, as shown in Table 6.

\begin{tabular}{|c|c|c|c|c|c|c|}
\hline \multicolumn{6}{|c|}{ Sum of SS Value Split } & \multirow[b]{3}{*}{ Grand Total } \\
\hline \multirow[b]{2}{*}{ Supply Chain Contributors } & \multicolumn{5}{|c|}{ Length of Lateness Classification } & \\
\hline & OTD Classification & $<=0$ & $<=14$ & $>14$ & No Delivery & \\
\hline \multirow[t]{4}{*}{ Procurement } & $100 \%$ & $\$ 18,370$ & 0 & 0 & 0 & $\$ 18,370$ \\
\hline & $80-90 \%$ & 0 & $\$ 22,648$ & 0 & 0 & $\$ 22,648$ \\
\hline & $<80 \%$ & 0 & $\$ 36,114$ & $\$ 26,519$ & 0 & $\$ 62,633$ \\
\hline & No Delivery & 0 & 0 & 0 & $\$ 3,519$ & $\$ 3,519$ \\
\hline \multicolumn{2}{|l|}{ Procurement Total } & 0 & 0 & 0 & 0 & $\$ 107,170$ \\
\hline \multirow[t]{4}{*}{ Manufacturing } & $100 \%$ & 0 & 0 & $\$ 72,778$ & 0 & $\$ 72,778$ \\
\hline & $80-90 \%$ & $\$ 22,394$ & 0 & $\$ 174,819$ & 0 & $\$ 197,213$ \\
\hline & $<80 \%$ & 0 & $\$ 25,884$ & $\$ 270,245$ & 0 & $\$ 296,129$ \\
\hline & No Delivery & 0 & 0 & 0 & 0 & $\$ 0$ \\
\hline \multicolumn{2}{|l|}{ Manufacturing Total } & 0 & 0 & 0 & 0 & $\$ 566,120$ \\
\hline \multirow[t]{4}{*}{ Assembly } & $100 \%$ & $\$ 1,441$ & 0 & 0 & 0 & $\$ 1,441$ \\
\hline & $80-90 \%$ & 0 & $\$ 29,749$ & 0 & 0 & $\$ 29,749$ \\
\hline & $<80 \%$ & 0 & $\$ 3,109$ & $\$ 7,678$ & 0 & $\$ 10,788$ \\
\hline & No Delivery & 0 & 0 & 0 & $\$ 192$ & $\$ 192$ \\
\hline \multicolumn{2}{|l|}{ Assembly Total } & 0 & 0 & 0 & 0 & $\$ 42,170$ \\
\hline
\end{tabular}

Table 6. OTD and Length of Lateness Matrix

As shown in the above table, some ranges selected for OTD and also for Length of Lateness to make the decision areas limited. OTD has been classified to on-time (OTD $=100 \%$ ), between $80 \%$ to $90 \%$, less than $80 \%$, and "No Delivery". On the other hand, Length of Lateness has been categorized to on-time or early deliveries $(<=0)$, late deliveries for less than or equal to 14 days, late deliveries for greater than 14 days, and "No Deliveries". In fact, at first glance, it 
may be concluded that parts located in the green area are good opportunities for safety stock reduction. However, it is clear that there should be other indicators to make the final decision in this regard. The required indicators are FFR, Safety Stock Coverage, and Quality Report. In what follows, we discuss the table according to the colored areas.

\subsection{Discussion for green area}

First of all, FFR is checked. If it is $100 \%$ then quality report will be checked for further investigation. If the part does not exist in the quality report, safety stock will be removed. But, if the part has had quality problems, then the days that the part stayed in the quality lot will be compared to the coverage days of the current level of safety stock. If, the coverage and days of quality report are equal, there would be no change for safety stock. If, coverage is less than the quality report days, then safety stock should be increased; otherwise, reduction in safety stock is required.

If FFR is not $100 \%$, again quality report will be checked. If the part does not exist in the quality report, more investigation required to find out the reason of not having the FFR of $100 \%$. On the other hand, if the part exists in the quality report, the same comparison as above for the days of coverage and days of quality problem will be done. If the coverage and days of quality are equal, we do not need to change the current level of safety stock; meanwhile, investigation is required as FFR could not be $100 \%$. One of the reasons for this could be that it is not able to fulfill the current safety stock level. If the part has not had quality issues, and the current coverage of safety stock is greater than the quality report days, it should be find out that why FFR is not still $100 \%$, although the kept level of safety stock is even greater than required. If the coverage is less than the quality days, safety stock level needed to be increased. This discussion can be found in the following flowchart (Figure 10). 


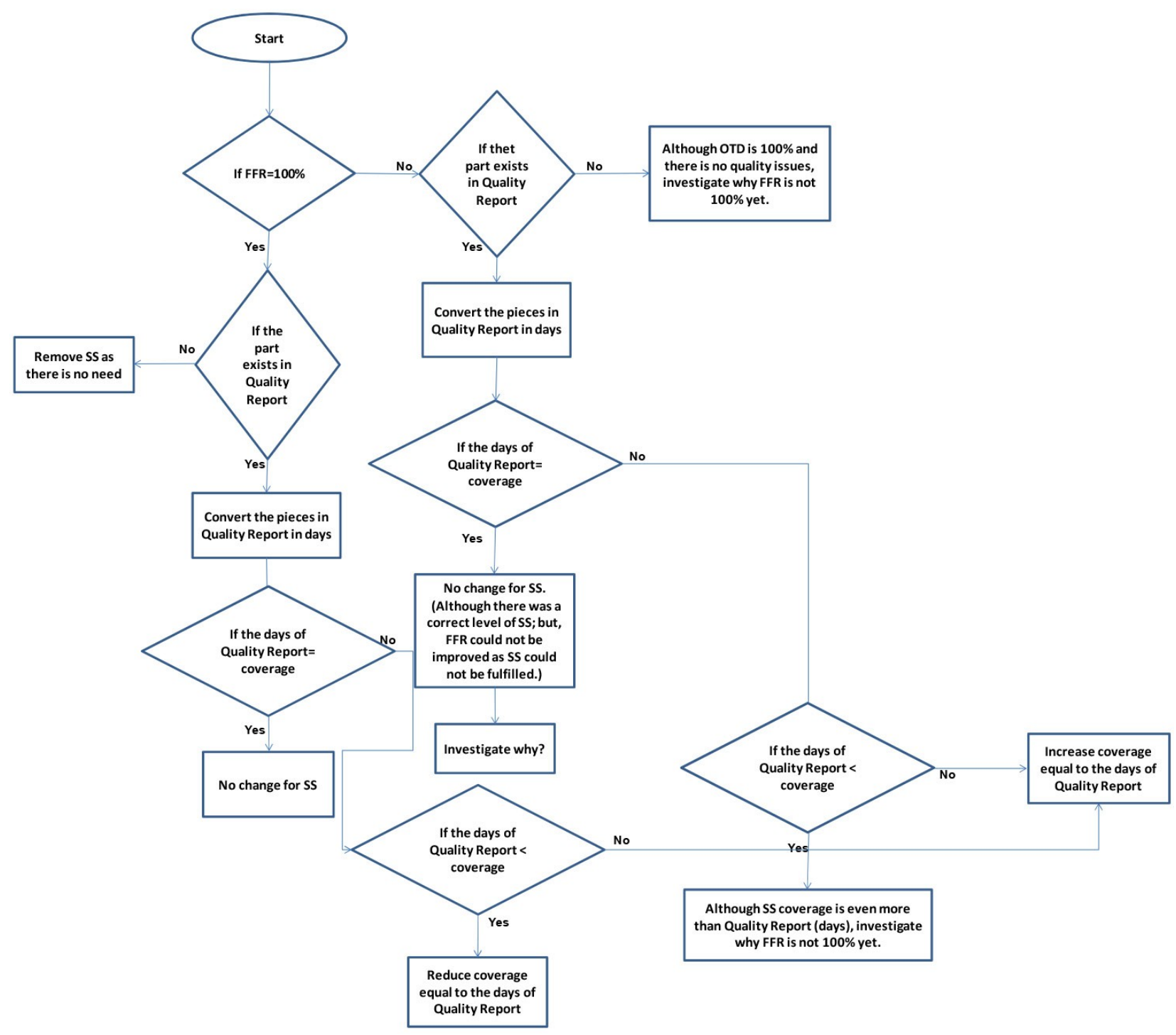

Figure 10. Green area flowchart

\subsection{Discussion for yellow area}

This area could be related to the parts that delivered in low frequencies but in big batches. Therefore, it cannot be concluded right away to remove the safety stock. Indeed, it is needed to making sure that whenever these parts arrive they do not have quality issues. Then, their safety stock can be removed; otherwise, removal of their safety stock will make the company to be in shortage.

\subsection{Discussion for red area}

As it is shown in Figure 11, initially it will be checked whether the part exists in the quality report or not. If yes, then FFR and OTD will be compared with each other. If FFR is less than OTD, we need to make sure that the current coverage covers the late delivery and also quality issues. If 
FFR is greater than the OTD, then it should be checked if FFR is $100 \%$ or not, and after that safety stock coverage should be compared with the quality report (days) plus lateness.

On the other hand, if the part does not exist in the quality report and FFR is less than OTD, we need to investigate the reason as there is no variability due to quality issues in this case and level of safety stock should be only equal to the lateness in the delivery. But, if FFR is greater than OTD, it should be checked whether FFR is $100 \%$ or not, and then safety stock coverage should be compared with lateness.

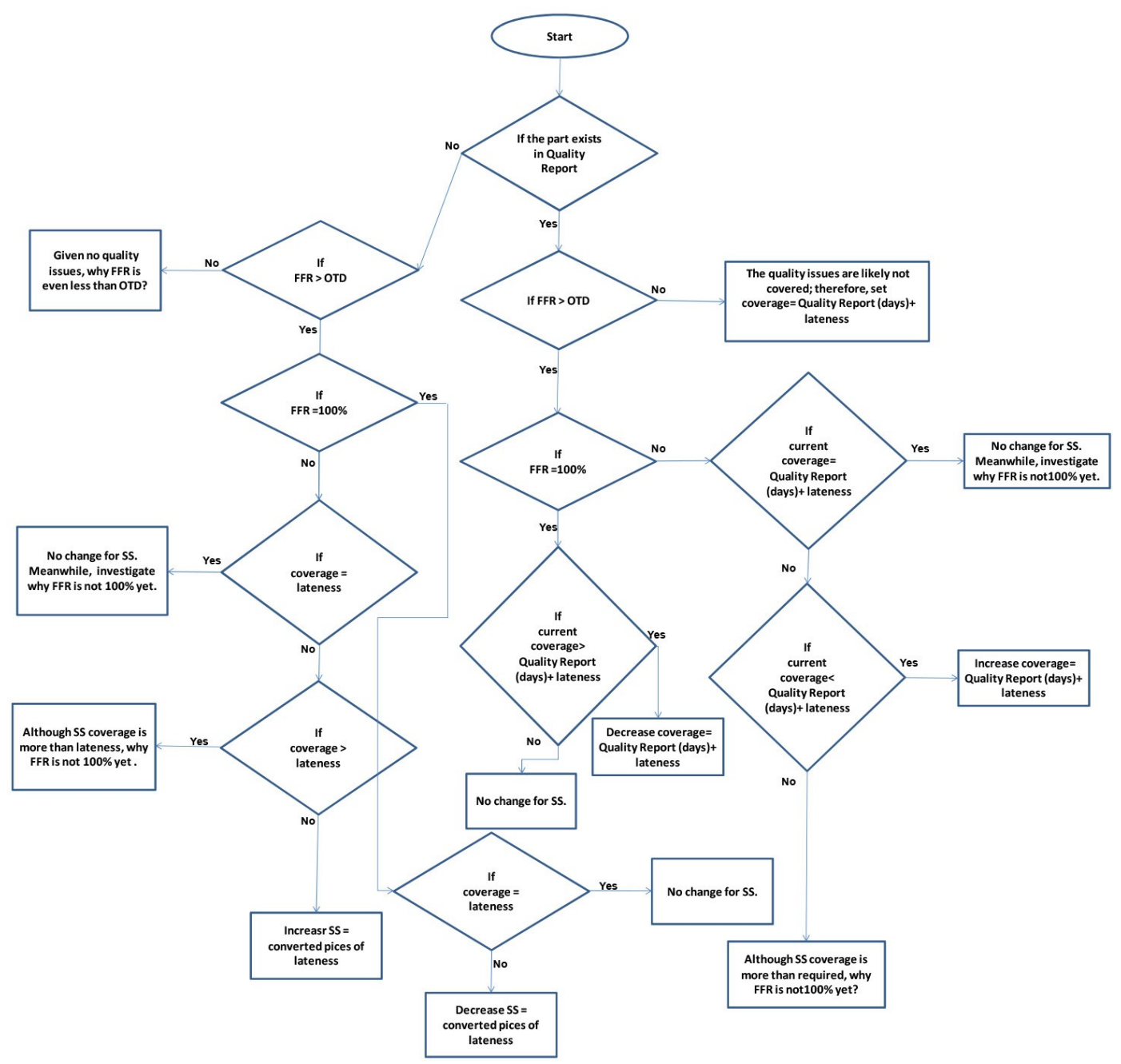

Figure 11. Red area flowchart

For calculating the days that the part was in the quality lot to compare it with the coverage of safety stock, "Duration in Quality Lot (in days)" and "Frequency of appearing the part in Quality Report" within last year for each part should be provided. Then, the days related to the "Maximum" of the frequency would be the representative of the days of being in the quality lot. If the maximum of the frequency is not unique, then the "Maximum" of their duration days will be selected. Table 7 shows this information that was gathered at the company. 


\begin{tabular}{|l|c|c|c|c|c|c|}
\hline Part A \\
\hline Duration In Quality Lot (in days) & 1 & 2 & 3 & 4 & 5 & 6 \\
\hline Frequency of appearing in the Quality Report & 2 & 3 & 5 & 10 & 9 & 1 \\
\hline
\end{tabular}

Table 7. Duration in Quality Lot (Days)

For the above sample, the maximum of the frequencies appearing in the quality report is " 10 "; therefore, its relevant duration which is " 4 " days will be selected to compare with the safety stock coverage.

Regardless of the result of the quality report (whether it is "Ok" or "Scrap"), the part has not been available for the specific period. So the system needs to be protected with the safety stock equivalent of that time of unavailability. On the other hand, if the result of the quality report was "Ok", the part released from quality report will be used to replenish the safety stock that was already used. Two samples (Tables 8 and 9) highlight the necessity of ALL metrics to make a correct decision about the level and location of safety stock.

\begin{tabular}{|c|c|c|c|c|c|c|}
\hline Part Code & $\begin{array}{c}\text { Safety Stock } \\
\text { (Pieces) }\end{array}$ & $\begin{array}{c}\text { Demand/Week } \\
\text { (Pieces) }\end{array}$ & $\begin{array}{c}\text { SS Coverage } \\
\text { (Days) }\end{array}$ & Length of Lateness (Days) & OTD\% & FFR\% \\
\hline A & 4 & 0.6 & 46 & 4 & $6 \%$ & $100 \%$ \\
\hline
\end{tabular}

Table 8 . Safety stock simulation model-sample 1

By only considering the above metrics for part A, it is concluded that safety stock has been helpful; but, as the coverage is greater than the length of lateness, it may be decided to reduce safety stock to make the coverage equal to the length of lateness. However, before moving towards reduction of safety stock, quality issues need to be considered. As FFR > OTD, we are sure about safety stock being helpful for part availability. However, a buffer stock is needed if there exist any quality issues for this part. Therefore, the quality report must be checked and if there are no quality problems, it can be concluded that safety stock should be reduced only to compensate the weakness of the supplier to deliver and company may survive even with less safety stock. On the other hand, if there is any record in the quality report that results in the part not being available, there is only a need to have safety stock equal to the length of lateness plus days of part the being in quality lot.

\begin{tabular}{|c|c|c|c|c|c|c|}
\hline Part Code & $\begin{array}{c}\text { Safety Stock } \\
\text { (Pieces) }\end{array}$ & $\begin{array}{c}\text { Demand/Week } \\
\text { (Pieces) }\end{array}$ & $\begin{array}{c}\text { SS Coverage } \\
\text { (Days) }\end{array}$ & Length of Lateness (Days) & OTD\% & FFR\% \\
\hline B & 1 & 0.5 & 14 & 8 & $53 \%$ & $94 \%$ \\
\hline
\end{tabular}

Table 9. Safety stock simulation model-sample 2 
In the above sample, although safety stock kept with the coverage which is greater than the depth of lateness, FFR is not still $100 \%$. Hence, we may conclude right away that there was a quality issue for this part. On the other hand, the reason that its FFR is not yet $100 \%$ could be due to having safety stock with the coverage which is less than the summation of length of lateness and the days that the part was in the quality lot. Thus, safety stock must be increased to become equal to the summation of the lateness and the days that part was not available due to the quality issues.

\section{Discussion and Implications}

The managerial guidelines and implications provided in this section are useful for any kind of manufacturing system.

Re-sourcing of the suppliers is a potential solution for those parts with low delivery performances and quality problems. For some cases where unavailability of a part is solely related to the low delivery performances and not to quality issues, safety lead time can be applied instead of safety stock. On the other hand, in the cases that the company requires keeping some level of safety stock due to the bad performance of vendors (low delivery performance, low quality), the VMI system is recommended to be applied to have safety stock at the vendors' place.

There may be some parts that are dual sourced and there is a quota arrangement between different suppliers, but the FFR report being used in the case company does not include the vendor field in its results. Therefore, it is recommended that the supplier field in the FFR report be considered as well to allow the company to recognize their delivery performances separately and consequently be able to make decisions about re-sourcing more accurately.

One of the other factors other than delivery performance or service level of the suppliers in making decisions in the dual source cases is the waiting time for receiving the late parts. Indeed, the company will select the supplier with the lower waiting time among the ones with the same service level. One way of tracking the waiting time of the supplier is through the calculation of the period within the replenishment lead time in that the company had negative stocks; but it is subject to keeping stock of each supplier separately to be able to relate its negative period to the corresponding supplier. Now consider a case that the supplier of a specific required raw material has the delivery performance of $50 \%$, demand is one piece per week, its replenishment lead time is 10 weeks, and its waiting time is 2 weeks. Assume that the worst case for its qi for the next quarter is 10 pieces. And again assume that it is the case that the model suggests keeping safety stock for the remaining $50 \%$ of the time that the supplier is late, which is equal to 5 pieces. This level of safety stock is equivalent to 5 weeks of demand, although the company will receive its late demand after 2 weeks according to the 
waiting time of the supplier. Therefore, the company does really need safety stock of 2 weeks instead of 5 weeks. Hence, no matter if it is a dual source case or not, it can be concluded that waiting time is also an important factor for determining the optimum safety stock.

If there is safety stock for the finished assembled product or it is scheduled for build ahead, sizing the required safety stock within the chain should be done by taking into account of these factors as well. One way to get them involved is by converting them to the weeks of demand for each stage and comparing them with the suggested amount of safety stock (like the method suggested for waiting time). But the time lag between the time that we put safety stock for the finished product or build ahead and the time that we will have it should also be considered; otherwise, reducing the safety stock within this period by counting on these factors will put the system in a shortage situation.

For some cases where unavailability of a part is solely related to the low delivery performances and not to quality issues, safety lead time can be applied instead of safety stock.

Delivery performances of some parts in their last stage are very low due to different engineering issues such as changing the layout and design consistently. Therefore, recommendation of the model to have safety stock for these parts will make sense only if the cost of rectifying of these parts is less than their shortage cost.

If the model suggests increasing the level of safety stock for a specific stage, the company will receive it by the end of the total lead time of the chain related to that part. Therefore, if the company adds the extra pieces of safety stock to its demand, it will allow all purchase orders to be expedited although this extra amount is not the actual demand and it is required for safety stock. Hence, the company must inform the suppliers that it needs this portion of demand for their next lead time. On the other hand, it is really important to take into account the lead time of the whole chain, otherwise, it will put them in a shortage situation. As a result, knowing the existence of this time lag by adding the required safety stock to the company's demand until receiving it through the chain, the period for calculating qi and qp can be selected more accurately. It should be noted that after selecting this appropriate period, standard cost of the parts should also be updated accordingly.

The safety stock optimization and simulation models developed in this research are applicable to any kind of manufacturing system that is moving towards applying lean principles. The safety stock models presented in this paper can be applied to create flow in their supply chain as well as to simultaneously reduce logistics costs. The optimization safety stock model in this study can be adjusted according to the requirements of different value streams of any supply chain. The safety stock simulation model in this research also addresses key metrics for supply chain performance measurement from which any system can leverage. 
The safety models developed in this research are applicable to any kind of manufacturing system that is moving towards applying lean principles. The models presented in this research can be applied to create flow in companies supply chain as well as to simultaneously reduce logistics costs and they can be adjusted according to the requirements of different value streams of any supply chain.

\section{Conclusions}

In this research, a safety stock optimization model is provided with the objective function of total logistic costs minimization to result in not only the optimal level of safety stock but also the optimal location of it across the supply chain. The constraints of the model provided for the boundaries of the delivery performances of each stage of the supply chain. Then, it is applied to a practical real-world problem with different possible value streams.

Providing supply chain performance measurement metrics that can be integrated is a challenging task. This study introduced some of these metrics such as First Fill Rate, On Time Delivery, safety stock coverage, among others. These metrics have been linked and a safety stock simulation model has been developed based on them. This simulation model supports the results of the optimization model for the optimal level and location of safety stock. $\mathrm{c}$

If a part is procured through more than one supplier, the current optimization model tracks their performance with only one average number representative of all of them. In future work, the model may be extended simultaneously by increasing the accessibility of the other required input data to decide on the level of safety stock for each of these suppliers separately.

Due to the inaccessibility of the required data, the optimization model is currently limited to the last two stages before the customer in the chain. Again, by enhancing the visibility and control of the upstream stages in the chain, the optimization model can be applied for each specific part from its starting point until the end of the chain. Furthermore, by increasing the accessibility of the data, the cost of shortage of raw material/semi-finished part can be more accurate by adding the re-sequencing cost of manufacturing. The cost of shortage of the finished part required by Assembly can also be more precise by making the average days of shortage weighted based on the frequency of its occurrence (increasing or decreasing trend of shortage).

One of the avenues for future work for this research would be taking into account the factors of waiting time for receiving the late parts, safety stock for the finished assembled product, and build ahead in making the decision for the safety stock. 


\section{References}

Adamides, E.D., Karacapilidis, N., Pylarinou, H., \& Koumanakos, D. (2008). Supporting collaboration in the development and management of lean supply networks. Production Planning \& Control, 19(1), 35-52. http://dx.doi.org/10.1080/09537280701773955

Aleotti Maia, L.O., \& Qassim, R.Y. (1998). Minimum cost safety stocks for frequently delivery manufacturing. International Journal of Production Economics, 233-236.

Cagliano, R., Caniato, F., \& Spina, G. (2004). Lean, Agile and traditional supply: how do they impact manufacturing performance? Journal of Purchasing \& Supply Management, 10, 151-164. http://dx.doi.org/10.1016/j.pursup.2004.11.001

Chen, I.J., \& Paulraj, A. (2004). Understanding supply cahin management: critical research and theoretical framework. International Journal of Production Research, 42(1), 131-163. http://dx.doi.org/10.1080/00207540310001602865

Chun Wu, Y. (2003). Lean manufacturing: a perspective of lean suppliers. International Journal of Operations \& Production Management, 23(11), 1349-1376. http://dx.doi.org/10.1108/01443570310501880

Coyle, J.J., Bardi, E.J., \& Langley, C.J. (2009). Supply chain management: a logistics perspective.

Crino, S.T., McCarthy, D.J., \& Carier, J.D. (2007). Lean Six Sigma for supply chain management as applied to the Army Rapid Fielding Initiative. In 1st Annual IEEE Systems Conference.

Desmet, B., Aghezzaf, E.H., \& Vanmaele, H. (2010). A normal approximation for safety stock optimization in a two-echelon distribution system. Journal of the Operational Research Society, 61(1), 156-163. http://dx.doi.org/10.1057/jors.2008.150

De Toni, A., \& Tonchia, S. (2001). Performance measurement systems: Models, characteristics and measures. International Journal of Operations \& Production Management, 21, 46-70. http://dx.doi.org/10.1108/01443570110358459

Graves, S.C., \& Rinnooy Kan, A.H.G. (1993). Logistics of production and inventory. Handbooks in Operations Research and Management Science.

Gunasekaran, A., Patel, C., \& McGaughey, R.E. (2004). A framework for supply chain performance measurement. International Journal of Production Economics, 87, 333-347. http://dx.doi.org/10.1016/j.ijpe.2003.08.003

Gunasekaran, A., Patel, C., \& Tirtiroglu, E. (2001). Performance measures and metrics in a supply chain environment. International Journal of Operations \& Production Management, 21(1/2), 71-87. http://dx.doi.org/10.1108/01443570110358468 
Inderfurth, K. (1991). Safety stock optimization in multi-stage inventory system. International Journal of Production Economics, 24(1-2), 103-113. http://dx.doi.org/10.1016/09255273(91)90157-0

Jung, J.Y., Blau, G., Pekny, J.F., Reklaitis, G.V., \& Eversdyk, D. (2008). Integrated safety stock management for multi-stage supply chains under production capacity constraints. Computers and Chemical Engineering, 32, 2570-2581. http://dx.doi.org/10.1016/j.compchemeng.2008.04.003

Kainuma, Y., \& Tawara, N. (2006). A multiple attribute utility theory approach to lean and green supply chain management. International Journal of Production Economics, 101, 99-108. http://dx.doi.org/10.1016/j.ijpe.2005.05.010

Lamming, R. (1996). Squaring lean supply with supply chain management. International Journal of Operations \& Production Management, 16(2), 183-196. http://dx.doi.org/10.1108/01443579610109910

Li, Q.Y., \& Li, S.J. (2009, July). A dynamic model of the safety stock under VMI. Proceedings of the Eighth International Conference on Machine Learning and Cybernetics, 1304-1308.

Long, Q., Liu, L.F., Meng, L.Q., \& Chen, W. (2009). Logistics cost optimized election in the manufacturing process based on ELECTURE-II Algorithm. In Proceedings of the IEEE International Conference on Automation and Logistics.

Maloni, M.J., \& Benton, W.C. (1997). Supply chain partnerships: Opportunities for operations research. European Journal of Operational Research, 101(3), 419-429. http://dx.doi.org/10.1016/S0377-2217(97)00118-5

Mason-Jones, R., Nalor, B., \& Towill, D.R. (2000). Lean, agile or leagile? Matching your supply chain to the marketplace. International Journal of Production Research, 38(17), 4061-4070. http://dx.doi.org/10.1080/00207540050204920

McCullen, P., \& Towill, D. (2001). Achieving lean supply through agile manufacturing. Integrated Manufacturing Systems, 524-533. http://dx.doi.org/10.1108/EUM0000000006232

Natarajan, R., \& Goyal, S. (1994). Safety stocks in JIT environments. International Journal of Operations \& Production Management, 14(10), 64-71. http://dx.doi.org/10.1108/01443579410067261

Naylor, J.B., Naim, M.M., \& Berry, D. (1999). Leagility: Integrating the lean and agile manufacturing paradigms in the total supply chain. International Journal of Production Economics, 62, 107-118. http://dx.doi.org/10.1016/S0925-5273(98)00223-0

Qi, F., Xuejun, X., \& Zhiyong, G. (2007). Research on Lean, Agile and Leagile Supply Chain. National Natural Foundation of China Grand and IOM European, 4902-4905. 
Silver, E.A., Pyke, D.F., \& Peterson, R. (1998). Inventory management and production planning and scheduling. 3rd ed.

Shepherd, C., \&, Gunter, H. (2006). Measuring supply chain performance: current research and future directions. International Journal of Productivity and Performance Management, 55(3/4), 242-258. http://dx.doi.org/10.1108/17410400610653219

Slack, N., Chambers, S., Harland, C., Harrison, A., \& Johnston, R. (1995). Operations Management. Pitman Publishing, London.

Taylor, D. (1999). Parallel Incremental Transformation Strategy: An Approach to the Development of Lean Supply Chains. International Journal of Logistics Research and Applications, 2(3), 305-323. http://dx.doi.org/10.1080/13675569908901587

Tempelmeier, H. (2006). Inventory management in supply networks. Problems, Models, Solutions.

Thomas, J. (1999). Why your supply chain doesn't work. Logistics Management and Distribution Report.

$\mathrm{Wu}, \mathrm{H}$. (2009). The Lean manufacture research in environment of the supply chain of modern industry engineering. 16th Conference on Industrial Engineering and Engineering Management, 297-300.

Wu, S., \& Wee, H.M. (2009). How Lean supply chain effects product cost and quality- A case study of the Ford Motor Company. In 6th International Conference on Service Systems and Service Management.

Xia, L.X.X., Ma, B., \& Lim, R. (2007). AHP Based Supply Chain Performance Measurement System. In Emerging Technologies and Factory Automation.

Zhao, X., Lai, F., \& Lee, T.S. (2001). Evaluation of safety stock methods in multilevel material requirements planning (MRP) systems. Production Planning \& Control, 12(8), 794-803. http://dx.doi.org/10.1080/095372800110052511

Journal of Industrial Engineering and Management, 2014 (www.jiem.org)

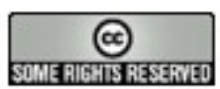

Article's contents are provided on a Attribution-Non Commercial 3.0 Creative commons license. Readers are allowed to copy, distribute and communicate article's contents, provided the author's and Journal of Industrial Engineering and Management's names are included. It must not be used for commercial purposes. To see the complete license contents, please visit http://creativecommons.org/licenses/by-nc/3.0/. 